\title{
From the Editor-in-Chief
}

\section{A New Journal dedicated to Hypertension is Born}

Dear Readers and Authors,

On behalf of the editorial board and the publishers, I welcome you to the inaugural issue of the 'Hypertension Journal'. It is my immense pleasure to serve as the Editor-in-Chief of this new journal, first of its kind in India/South Asia. The aim of the journal is to provide scientific information in a scholarly manner. Since hypertension is multifactorial in terms of etiology and manifestations, the new journal will strive to provide a better understanding of various diversified perspectives of hypertension. The journal will publish research articles, reviews and case reports to enhance the knowledge base of healthcare providers

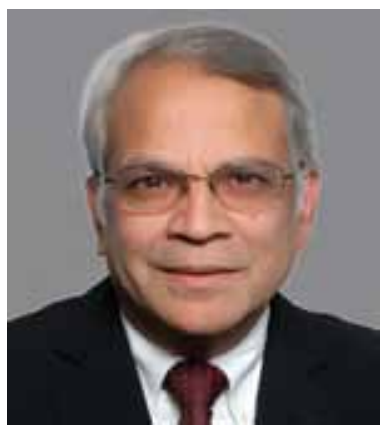
dealing with hypertension. I would encourage you to submit your reviews, concepts, commentaries and original work for publication in the journal.

Hypertension is a major health problem in India and South Asia. The ravages of untreated hypertension are well known to you and so are the benefits of blood pressure reduction. The question has been how to bridge scientific advances and vast knowledge with clinical practice. To resolve this question, the 'Hypertension Journal' is born. The editorial board and the editorial consultants represent all scientific disciplines and specialties linked to hypertension directly or indirectly. We believe that such a broad-based team will fulfill the expectations of doctors and other healthcare providers who treat patients with hypertension.

Again, a warm welcome on behalf of the 'Hypertension Journal'. I hope that the journal will be the voice of hypertension in India and South Asia.

C Venkata S Ram MD MACP FACC FASH

Editor-in-Chief

Hypertension Journal

Director, Apollo Institute for Blood Pressure Management

Director, Blood Pressure Clinics, Apollo Group of Hospitals

Andhra Pradesh, Hyderabad, India

Director, Texas Blood Pressure Institute, Dallas, Texas, USA

Director for South Asia Region

World Hypertension League (in partnership with WHO) 